\title{
The role of positive psychology interventions to reduce psychological problems associated with COVID-19 pandemic: Prevention and Therapy Approach
}

\author{
Boshra A. Arnout ${ }^{1,2}$ \\ ${ }^{1}$ Department of psychology, King Khalid University, Saudi Arabia, Abha. \\ ${ }^{2}$ Department of psychology, Faculty of Arts, Zagazig University, Egypt. \\ DOI:
}

\begin{abstract}
This study aimed to reveal the role of positive psychology in treatment mental problems and disorders related to COVID-19. Also, to detect the strategies of positive psychology that benefit to reduce the distress related to crisis of COVID-19 of individuals. A review of the literature and previous studies that dealt with positive psychology interventions and their effectiveness in treating mental disorders. The outbreak of the COVID-19 pandemic affected the well-being of the human being has led to an increase in the role of face to face and online counseling and psychotherapy, based on different theoretical approaches, and by using various techniques derived from positive psychology such as mindfulness, resilience, gratitude, acceptance and commitment, spiritual intelligence with individual from different age groups. As well as we need to apply the VRT with persons with mental disorders related to COVID19 outbreak. Also, an acute need for counselors and psychotherapists aroused to meet the counseling, preventive, and therapeutic needs of community members. States require to strategic planning to meet the great challenges resulting from this pandemic and need to develop new policies to provide effective psychological services to members of society. Positive psychology interventions is very important to reduce the psychological problems and post-traumatic COVID-19 disorders. Thus, we need to develop a training plan for psychological services providers on the theories and techniques of online psychotherapy, and VRT principals, to empowering them to provide effective services. Moreover, we need necessary to develop an ethical charter for online psychotherapy.
\end{abstract}

Key words: COVID-19, positive psychology, quality of life, spiritual intelligence training, mindfulness training, resilience training, ACT, gratitude training VRT.

\section{Introduction}

\section{COVID-19 pandemic and quality of life}

The concept of quality of life reflects the individual's sense of happiness, sadness and joy stemming from his satisfaction with his health, psychological, social and health status. The concept of quality of life includes all the different aspects of life, happiness and satisfaction with life, such as health, psychological, physical, 
social, family and work relations. There is no doubt that this outbreak of the COVID-19 pandemic and the precautionary measures taken by countries, such as home quarantine, total or partial bans or curfew, and the closure of schools, commercial malls and entertainment venues, have an impact on the individual's well-being and enjoyment of life.

The previous studies revealed that in the longterm exposure to traumatic events leads to a range of serious mental health problems (Dirkzwager et al., 2003). In addition, Dubey et al. (2020) found that the COVID-19 outbreak caused many social and psychosocial distress that affect people's well-being negatively. Klug (2020) reported that the psychological distress will increase due to the continuous rapid news about the number of COVID-19 infections and deaths. As well as Arnout et al. (2020) found that the increased prevalence of COVID -19 has a negative effect on the mental health of individuals. The media's loud voice about the outbreak of the deadly COVID-19. On the other hand, individuals seemed to exaggerate the hygiene and excessive caution in the infection, which increased the prevalence of obsessivecompulsive disorder.

In addition, the quarantine imposed on individuals as preventive procedures against COVID-19, grief appears which is the emotional and behavioral response to any loss, and this does not include the loss of loved ones only, it also includes the loss of property and personal freedom, along with illness, unemployment and ending a relationship. Sadness divided into five stages that include initial trauma, emotional numbness, denial, followed by a period of anger, then sadness and depression, and finally acceptance. And with the prolonged quarantine period, the course of sadness may go out of the ordinary or in the event of tragic events such as natural disasters, or if symptoms of depression appeared in a previous stage of sadness, or in the event of misuse of alcohol and narcotics (Arnout 2020c; Arnout et al., 2020).

Moreover, the health care providers suffer from many psychological problems. The study of Lancee et al. (2008) found that $30 \%$ of health care workers reported depression, anxiety or drug use during the SARS outbreak. While the study of Bai et al. (2004) indicated that $5 \%$ of health care workers reported PTSD. Liu et al. (2012) found $9 \%$ of health care providers reported high level of depression. Recently, the study conducted by Chen et al. (2020) indicated that health care providers reported high levels of fear, anxiety, depression, distress.

Therefore, Vostanis \& Bell (2020) reported that "the world has entered unchartered waters that only time and history will make sense of. We may not even be at the beginning of a chain of events and changes that will define at least the next generation. This is no excuse for not attempting to anticipate the impact on each one's field, or to articulate how we should respond in likely scenarios. So, what does this new era hold for counselling and psychotherapy? Crucially, where should counselling and psychotherapy 
position themselves to respond to evolving population needs?".

2. Positive psychology and the therapy of the psychological problems related to COVID-19

Positive psychology came to present a scientific trend that focuses on human capabilities and aspects of human powers and virtues. Positive psychology belongs to the first group that was mentioned first, because it is primarily interested in the scientific study of what brings happiness to people. It seeks to enhance the multiple personality capabilities, such as steadfastness, psychological rigidity, positive thinking, etc., and to train individuals to face the psychological stress they are exposed to, to get rid of psychological combustion, to improve satisfaction with life and quality, and to study conditions and processes, which contribute to achieving the highest performance functional for people, groups, and institutions (Arnout 2019a). Moreover, positive psychology, in its interest in society, seeks to develop virtues and activate the role of civil institutions, which work to improve reality and develop a sense of responsibility among individuals, altruism, tolerance, and creative work. This is why the important and essential role of positive psychology in treating mental disorders resulting from the pandemic disturbance COVID-19 is highlighted (Arnout 2020c).

Positive psychologists provide life counseling according to principles that research has shown to be successful. Some of these principles include a passion for achieving positive outcomes, achieving an abundance of positive energy in relationships, facing challenges with optimism, using strengths to achieve goals, renewing energy to achieve goals, and making a difference in the world. If positive psychologists have tried and learned these principles, it is easier for them to advise others to do the same and have the change they want to see in the world. Supporters of the positive psychology movement believe that one can learn to be happy. Therefore, in light of the outbreak of the COVID-19 pandemic, people are in urgent need of positive psychology applications in protecting them from exposure to psychological problems that may result from the quarantine and social separation imposed on them, as well as for the treatment of individuals with mental disorders associated with the distress of the COVID-19 pandemic (Cicchetti 2010, Duckworth et al., 2005, Seligman 2002, Seligman et al., 2006).

\subsection{Psychological Resilience Training (PRT) through the COVID-19 pandemic}

Psychological resilience in times of crisis is the ability to change attitudes and actions to take when new or unexpected events emerge. This skill enables us to deal more easily with difficult crises and situations, without the need for long periods of time. This skill is already used in our daily lives, when we deal with, for example, changes in the work agenda at the last minute, or you need to change working hours when one of the children is sick, for example, or the need to re- 
prioritize during transitional periods, such as the period of leaving the job when there are no other alternatives available, stressing that maintaining and improving a flexible mindset will be a critical skill for us, as an alternative to despair and chronic anxiety (Cicchetti 2010, Fernandez 2016, Gilbert 2016, Graham 2013, Griffith \& West 2013, Kim-Cohen 2007).

In general, humans are remarkably resilient, as some individuals have experienced much worse situations and conditions of life than mankind now, although the situation is undoubtedly difficult now, yet they were able to overcome the matter and return to their normal nature before they passed the crisis (Cicchetti 2010, Dirkzwager et al., 2003, Kluge 2020, Kummons 2016, Yeager \& Dweck 2012).

2.2. Mindfulness Training (MFT) through the COVID-19 pandemic:

In psychoanalysis and philosophy, there is an idea that is growing and popular that an observant observer can find, which is related to the importance that the mind occupies, and looking at mindfulness as a special treatment today, which is full of problems, stress and calamities. The basic idea in mindfulness-based exercises is to immerse yourself in the present and learn the art of selfdiving (Baer 2006, Beddoe \& Murphy 2004, Brow \& Ryan, 2003). Arnout (2020c) mentioned these exercises, which are based on developing mindfulness of individuals can be useful to treat psychological problems associated with the COVID-19 pandemic.
Also, in mindfulness training, the individual can learn the art of filling a void, but only by himself. In the sense that, in order to be sufficiently alert to the world and the things around it, one has to dive into it, to stop, even temporarily and temporarily, from thinking about all the fear/anxiety and anxiety caused by the home stone, and to sit quietly and complacent, enjoying the emptiness and emptiness (Baer 2006, Teasdale et al., 2000). Fleeing and resorting to the moments of complete emptiness are, in depth, the station to which one returns to be energy and to recharge himself again. What needs to make an individual under pandemic conditions COVID-19 in order to be happy, is nothing but what he really has, but only on condition that he pay attention to this that he owns, and optimize his use; wisdom is the ability to "deplete the essence of things." Home quarantine is required to preserve our health, and protect us from infection with this deadly virus, and it must come and end one day.

Man possesses only the present, only those moments that he now lives. The past is past and the future is unknown, but a lack of awareness of these facts will put people in serious trouble; Including, for example, addiction to looking at the past and its tragedies, and wasting the present which we have no other - in regret over a past that we no longer have. Not only that, but this pathological attachment to the past and the memories and tragedies involved in it, will negatively affect our ability to be artistic in the present, and our health as well. And the future as well, has not yet come, and as long as it is in the 
rule of the unknown or so, indeed, thinking about it, fear and anxiety about it is pure stupidity (Baer 2006, Teasdale et al., 2000).

\subsection{Mediation Training (MT) through the COVID-19 pandemic}

Meditation helps us know ourselves, restore our ability to control our thoughts and feelings, and our ability to distinguish between truth and illusion becomes more accurate, and as a result we make smart decisions. Also, observation, which is the ability to have a clear vision and a deep understanding of what is going on around us and what is happening inside us, makes us able to monitor our thoughts and beliefs. This allows us to be more aware of the relationship between the inner world than thoughts and feelings and the outside world and the implications (Kabat-Zinn 1990, 2000).

Many people under conditions of home quarantine and social spacing, who have negative attitudes believe that bad things happen to them because they are making a mistake one way or another, and they see the worst possibilities in every event, this situation often leads to shifts in the hormonal system or immune system, which could put them at greater risk of developing COVID-19.

The ultimate aim of meditation, rather than looking at mindfulness as a therapy, as with every other meditative exercise, is that one knows himself, but accessing this particular knowledge is by no means easy, but if one is lucky and manages to find himself, everything will change in him and around him. Among the most pleasing results one can achieve, by knowing oneself, being more aware of others, more respectful of them, and compassion for them (Baer 2006,

\section{Brow \& Ryan 2003, Kabat-Zinn 1990).}

Although this aspect shows the altruistic aspect of a person, it involves personal gains and personal benefits at the same time. If, under conditions of quarantine and social separation, members of society are able to realize that they are just part of every large, and that the home is nothing but a grain of sand on a large beach, then they despise their problems, stress, and the anxiety and fear that they are going through due to the spread of the COVID-19 pandemic, and they will be more flexible to handle (Arnout 2020c).

Also, contact with great spiritual powers enables us to realize our role in this universe, and then helps us to get rid of mental disorder in our minds, and be more aware and aware. And the practice that refers to putting knowledge and learning into practice, acquiring new visions and accomplishments and new forms of expressing ourselves, all of this theoretical aspects that have no ability to change our lives unless they are translated into actions and actions that allow us to form new behaviors and visions. In these difficult times, people can be trained in home quarantine and social estrangement, for those who have meditated for three months have shown less anxiety, stress, job satisfaction, and improved personal and professional relationships compared to the control group members who did not 
meditate (Beddoe \& Murphy 2004, Jain et al., 2007, Kabat-Zinn et al., 1992).

According to Baer (2006), Brow \& Ryan (2003) and Teasdale et al. (2000) there are five important steps for meditation:

1. Adhere to the full truth with love.

2. Practice whenever possible.

3. Stop believing in your thoughts.

4. Dive deep into your soul.

5. Live as if the future is in your hands.

Meditation helps individuals and health, and psychological care providers know ourselves, restore our ability to control our thoughts and feelings, and our ability to distinguish between truth and illusion becomes more accurate, and as a result we make smart decisions. Also, observation, which is the ability to have a clear vision and a deep understanding of what is going on around us and what is happening inside us, makes us able to monitor our thoughts and beliefs (Baer 2006, Teasdale et al., 2000, Jain et al., 2007).

\subsection{Spirituality Training (ST) through the COVID-19 pandemic}

In today's world with the outbreak of the COVID19 pandemic we need to pay attention to this aspect from the theory as well as the process by developing training programs to develop the spiritual intelligence of man, especially as we all live in a world full of conflicts, squabbles, disasters, crises and stress in the family, work and school as well as the stress resulting from quarantine and social separation to prevent
COVID-19 infection. Therefore, we find there is a global and international interest in human development, in line with the fact that the nature of man is good, as he by nature loves life and others around him. Man is social, compassionate, cooperative, tolerant and realizes God's great blessings on him, but all these positive attributes have been lost in the shadow of daily life with its problems, for only a person needs guidance and guidance that makes him restore confidence in himself again and in others and accepts life with all its advantages and disadvantages because it is a gift from The Creator, in other words, develops his spiritual intelligence and spiritual skills, wakes up from his spiritual negligence, and restores his humanity again.

Because spiritual intelligence is the main driver of a person who always directs him towards doing good and worshiping the Creator with certainty and reverence, and therefore his lack makes a person mislead and becomes a prisoner of his desires and needs and leads astray from the right path, and plunges into the fullness of his pleasures and minimum physical needs, which causes him to dive into His minimum or muddy qualities, while his preoccupation with satisfying his soul and soul alongside his body, by performing rituals and maintaining prayer, rituals, thanksgiving and reverence to God and the love of others and dedication in helping them, makes him increase his purity, spirituality and transparency and his qualities approach angelic qualities (Arnout 2016, Arnout 2019b). 
Arnout (2020c) said that "it is necessary in light of the COVID- 19 pandemic that the development of a good and free citizen with a will, belief and faith is important, and the individual who lives in peace is one of the most important goals of education and mental health that societies seek to achieve in individuals and cultivate them in adolescence from an early age. The development of the spiritual side is one of the requirements of mental health in all stages of human development, from childhood to old age. Our Islamic religion is keen on raising the spiritual side of a person in his early stages of life, such as teaching the newborn the word of unification through the ears in the ears of the newborn immediately after his birth, as well as the duty of parents in He taught him matters of worship and established Islamic morals in his personality in the early years. The development of spiritual intelligence helps us to see the pleasant and fun side of things, and increase our inner peace with ourselves, which makes the individual more able to control ourselves and relieve the stress we face in our contemporary life, which is characterized by its fast rhythm".

The development of spiritual intelligence is not only for adults, but also spiritual development must be developed among children, that the child must be raised to help him develop stronger relationships, learn how to live a happier life, and how to absorb religious fruits through parents, so parents must They are aware of their role in developing the spiritual intelligence of their children and their duty to do so. They must also warn that fear not only hinders this process, but leads to the spiritual ruin of children and wastes the value of moral training (Arnout, 2016). Our understanding of the context and significance of our actions in light of the spread of the COVID19 pandemic, enables us to make more informed choices than to make us slaves to a steadfast response to the requirements of life. Accordingly, the development of spiritual intelligence enables the individual to express unspeakable moments that unleash inner spiritual energy (Arnout 2020c).

The recommendations of the seventh annual conference for training in the Arab world came that emphasized the importance of the spiritual aspect as a pillar in the development and the development of human resources. Because the development of the spiritual side makes the person in constant contact with God and then gives the human life the true value of his existence and gives him hope, happiness, optimism and a vision of the bright and bright side of people, things and the entire universe, for a person is honored with his universal humanity, from body, soul and spirit (Arnout 2016). In light of the foregoing, and due to the changes that occurred in the needs of society, the conditions of pandemic outbreaks remained as a COVID- 19 and what was imposed on individuals from home stone and social separation, and because the real wealth of any society is its human wealth, health, intelligence, clarity, purity and tolerance of its members, attention must be paid to developing the spiritual intelligence of individuals to 
strengthen their psychological immunity, such as their sexual immunity, to face the stress of the pandemic of an outbreak of pandemic COVID19 (Arnout 2020c).

From the above, we concluded that the individuals in light of the spread of the COVID19 pandemic, are needed to the spiritual intelligence training, because this training learns them to develop the following:

1. Resilience: It refers to a person's resilience and his ability to view the world as a diverse and realistic reality, and it is concerned with the individual's ability to integrate, understand and adapt according to developments.

2. Self-awareness: As people with spiritual intelligence have self-awareness and are able to look internally to see who they really are.

3. An ability to confront and learn from experiences of failure and the things that they fear.

4. An ability to look at the connections between different things and group thinking.

5. An ability to work and be independent in scope.

The development of skills of spiritual intelligence goes through stages, starting with the application of individual spiritual practices such as relaxation and meditation to reach awareness, meaning and spiritual sublimation, and then these practices are reflected in the individual's surroundings and people notice them in his behavior of acceptance, forgiveness, and moral uprightness. Reflecting the individual practice of spiritual intelligence on public behavior requires time, effort and social

reinforcement (Amram 2007, Arnout 2016, Arnout 2019b, Hartwick 2013).

Thus we can say that if we can preserve characteristics of the individual in the light of the pandemic of COVID-19, and we helped him to get rid of his negatives and minorities, and we changed what needs to be changed, and we repaired the existing deficiencies and shortcomings, and we overcome the mental, emotional and psychological obstacles and obstacles, then we make The individual is prepared to increase his spiritual energy, but only on condition that he adhere to and maintain behavioral changes even if they are simple. Because the simple, long-term method of change brings us to achieving our goals of increasing the psychological immunity of individuals so that they can face the stress associated with the COVID-19 pandemic. This method is the most effective in making changes and achieving goals through indicative and treatment interventions (Arnout 2019b, Arnout 2020c, Hartwick 2013). In light of the conditions of COVID-19 pandemic, spiritual intelligence is linked to mental health in general, it helps to psychological stability, understanding the self and others, and is linked to what is best in all matters, and the pursuit of good and benefit for the self and society, and its importance can be explained in the following:

1. It helps the individual to go and worship God Almighty with sincerity and certainty.

2. It makes man abide by virtues. 
3. It makes man feels the reward for what he does best.

4. It makes man's life a worship, because worship is nothing but a process of developing the angelic essence in the human spirit.

5. It is a magical elixir suitable from the whims of the human soul and its evil tendencies.

6. It helps the person to realize the correct principles that are part of his conscience and that are similar to the compass directed to do good things and avoid sins and sins.

7. A basis for building personality without which man loses many noble meanings and loses positivity.

Many researchers consider that spiritual intelligence is the most important type of intelligence because of its ability to influence people and change in cultures and societies. Therefore, interest in developing spiritual intelligence helps individuals under pandemic conditions as COVID-19 to adopt a positive view and achieve internal peace, as it improves It is motivated by self-control, in addition to reducing high levels of stress from life in pandemic conditions COVID- 19. This is because spiritual intelligence is a functional ability for every person who can learn to reach it. It is not something strange, supernatural, or specific to a small group of individuals and not others, and since it is not prevalent, it may appear to some as a mysterious or esoteric ability. The development of spiritual intelligence provides the individual with various ways to make unusual changes in his life, and it also helps him to determine the appropriate time to make these changes (Amram et al., 2008, Arnout 2019b, Arnout 2020b, Buzan 2001, Hartwick \& Kang 2013).

Research in positive psychology indicates that spiritual strength in crises, such as the COVID19, can be important in helping individuals overcome and overcome crises and losses. Facing difficult challenges in life inspires individuals to think more deeply about their religious and spiritual beliefs and the meaning of life. Spirituality, religion and faith have also been proven to have roots associated with resilience outcomes among people suffering from adversity, violence and psychological trauma such as those experienced by many members of society due to the distress of the pandemic of COVID-19 (Arnout 2019c, Arnout 2020c).

Buzan (2001) has identified ten steps to develop a person's spiritual intelligence. These steps can be used to develop the spiritual intelligence of individuals in the conditions of COVID-19, which are:

1. That the person realizes the full picture of the universe.

2. Looking for your values.

3. Create a plan for your life and goals.

4. Empathy for oneself and others.

5. give and take, kindness and gratitude to others.

6. Laugh out loud.

7. I play like children.

8. The power of rituals and acts of worship.

9. Peace.

10. What you need is love. 
Costello (2013) introduced three steps to increase spiritual intelligence. These steps we can applied to develop the spiritual intelligence of individuals under the COVID-19 pandemic, as follows:

1. Integrity: That the individual learns his personal values and how to be loyal to these values and beliefs and his conscience, and then lives in his life with these values. Likewise, he must fulfill the promises that others have made, and maintains his personal obligations, and all this increases his ability to abide by the covenant, and gradually moves from simple obligations to larger obligations, because this provides him with a great source of strength and intelligence.

2. Bring Meaning to Your Life: Do it for others and for reasons that you think are worthwhile. Ask yourself what can you offer others in your life?, what do they want from you ?, how can you use the wisdom, skill, and talent that you have in helping others, and how can you contribute to the well-being of others. Whenever you give more things to others, as you bring value and meaning to your life, I start with the little things, then move from them to the bigger. And when you have things to do for others, this is a source of your personal strength and intelligence.

3. Give a voice to your Values: by linking your work with your own talents and abilities, and what life means to you. Set a vision for your life that will inspire and guide you, participate in important and exciting work for you, learn to love what you do, make your work allow you to be a complete person. Use your four intelligences (cognitive, social, emotional, spiritual) to live your life and enjoy your day, and at this time you will become a great source of your personal strength and intelligence.

The development of spiritual intelligence for individuals and health and psychological care providers creates an enlightened focus on our current reality, and this undoubtedly helps us in answering the major questions in life, and thus facilitates the achievement of personal integration, and this perfection is what makes us enjoy peace and enhances personal integrity, which gives us greater ability to a life of full meaning and meaning. Therefore, developing spiritual intelligence is a goal for everyone in this world (Amram et al., 2008, Arnout 2008, 2016, 2019b, 2020b, Buzan 2001, Hartwick \& Kang 2013).

\section{Online counseling and psychotherapy}

In the light of quarantine, online counseling and psychotherapy must be activated, which is providing counseling services in the field of mental health through the Internet, and services are usually provided by e-mail, chat, and video conferences, as some clients use online counseling in conjunction with traditional psychotherapy, or nutritional counseling (Arnout 2018).

As well as the forms of telephone counseling that have been available for more than 35 years. The emergence of video chat systems on the Internet 
and increased Internet connectivity have led to a growing movement towards online therapy, as clients use videoconferencing, live chat and email with psychologists in place of or in addition to face-to-face therapy to prevent transmission of COVID-19. Especially after a growing body of research in online counseling has reached the efficacy of online therapy, with treatment outcomes at least equal to traditional methods (Arnout 2020d).

Online therapy generally has additional unrealized benefits in traditional treatments as it allows the patient to attend sessions at a higher rate than traditional courses. Also, the number of missed appointments is much lower than traditional direct treatment. There is some research indicating that online counseling is more effective because the client feels easier and less intimidating than if he is in traditional treatment environments. This makes the client more likely to be honest, thus allowing the consultant to provide the best treatment. Under the conditions of quarantine, the provision of psychological services via the Internet is useful in reducing the infection rate of the COVID-19, as well as providing these services to those who need them, at a time that suits them, and in the manner available to it. This reduces possible injuries from mental disorders caused by disturbance of COVID-19 and the associated stresses resulting from quarantine conditions. Also, online counseling and therapy is beneficial for people with different physical, mental, auditory and visual disabilities, and also for the elderly who are considered to be the most psychologically affected case of the COVID-19 pandemic (Arnout 2018, 2020c, 2020d).

\section{Gratitude Training (GT) through COVID-19 pandemic}

The study of positive emotions and their impact on people's health is a much more important topic today. One of these positive feelings is gratitude (Mikulincer \& Shaver 2008). Although the search for gratitude is relatively new (Lambert $\boldsymbol{e t}$ al., 2009). A systematic review by (McCullough et al., 2001) shows evidence that gratitude encourages positive social behavior, such as strengthening social networks and friendship, as well as contentment with life and happiness, it represents a broader attitude towards observing and appreciating positivity in life (Wood $\boldsymbol{e t} \boldsymbol{a l}$., 2010).

Gratitude is indispensable in a person's life, and the individual feels isolated and lonely if his ability to feel gratitude is weak (Emmons \& McCullough 2004). Gratitude stimulates interpersonal exchange of help and support (Bartlett \& DeSteno 2006, McCullough et al., 2001, Tsang 2006). As Melanie Klein (1963/1975) stated, gratitude can alleviate loneliness because it involves a very close relationship between the ability to accept and give in individuals. That is why the expression of gratitude plays an important role in human relationships because it can enhance social ties and friendships (Emmons \& Shelton 2002, McCullough \& Tsang 2004). 
Gratitude is the key to our entire life through COVID-19 outbreak, it makes us feel that what we have is enough for us, and more than that, it turns denial into acceptance and gratitude, chaos into order, and confusion into clarity. He turns interpersonal problems into love and gift-giving, failure to success, and the unexpected into his realization that it came at the right time, and mistakes into important events. Gratitude makes us think logically and rationally about our past, it brings peace for today and creates vision for tomorrow. Lopez \& Snyder (2003) stated that the word gratitude is derived from the Latin word Gratia, which means grace or gratitude.

\section{Acceptance and commitment therapy through} (ACT) COVID-19 pandemic

ACT is appropriate for people who struggle with extreme living conditions. Among the important applications of ACT is its use to increase the quality of life, and to increase individuals' awareness that avoiding or escaping from stressful situations is what makes them not lead the life they desire, and in order to lead a comfortable life, they are obligated to change their behaviors and ideas (Arnout et al., 2019;

\section{Orsillo \& Batten 2005).}

Regarding the effectiveness of ACT, previous studies have demonstrated its effectiveness in developing psychological well-being and reducing anger, anxiety and symptoms of bullying. For example, the study conducted by (Saeed et al., 2016) revealed the effectiveness of a program based on ACT in developing personal happiness and reducing test anxiety among secondary school students. As well as, the results of the study conducted by Tabrizi \& Nameghi (2017) showed the effectiveness of ACT in improving psychological well-being and reducing anger in mothers of deaf children. Bahreini, Sanagouye-Moharer (2019) and Bayati et al., (2017) also found the effectiveness of ACT in developing psychological well-being. A series of recent studies have begun to evaluate the effectiveness of online ACT, and its results have shown its effectiveness in reducing depression, smoking, chronic pain and mental health problems and improving academic success, anxiety, and mental health problems in individuals (Levin et al., 2016). Arnout (2018) conducted a study, results showed the effectiveness of online ACT in reducing symptoms of job bullying and the survival of the program's effect during the follow-up period for the experimental group. Also, the study of Arnout (2019d) found the ACT is effective in improved the personality strength traits.

\section{Virtual Realty Therapy (VRT)}

With the rapid technological and technological development that we are witnessing in our current age, and the quarantine witnessed by the world as a preventive procedure against COVID-19, it has become easier to obtain the many benefits by using these technologies and in various fields, including the area of health and psychological services. VR plays a form of technological development, and it has had a prominent role in 
the treatment of organic and psychological diseases, as well as the rehabilitation of patients and enabling them to return to their normal lives. The role of VRT grows in light of the prevalence of anxiety, fear, depression and social phobia, with conditions of sanitary quarantine and social distancing (Arnout 2020c, Gorini \& Riva 2008). The previous studies indicated the importance of the VRT in relief anxiety (such as Gorini \& Riva 2008) and improved the quality of life (such as Anderson et al., 2001; Rizzo et al., 1997).

\subsection{Definition of VRT}

VR is an evolving type of human and computer interaction that allows the user to interact with a virtual environment created through a computer that simulates the interactive environment. The main goal of using VR is to reduce the negative effects that may occur to a person when experiencing the real reality, as well as exposing the individual to situations he is afraid of in reality, and then the virtual coexistence reduces anxiety, phobia and phobia. And therapy with VR allows the repetition of specific exercises at times that suit the individual, as it provides a safe environment for the individual during the practice of therapeutic exercises, which reduces his stress and fear, as well as that the VRT exercises are exciting, fun and help to recover, and for this is appropriate for this period in which anxiety has risen And concerns due to quarantine and social separation (North et al., 1997; LVZ et al., 2016;

Riva et al., 2016; Rizzo et al., 1997).
VR refers to the assumption of something reality, so what is displayed on computer screens, and we see it using physical devices, we assume it is reality, and this is related to the process of visual imagination, and the term VR is the most frequently used term to refer to VR technology. $\mathrm{VR}$ as an interactive computer environment, in which the individual is more interacting with images, which is an advanced technology that provides panoramic displays related to three dimensions: represented in the eyesight, hearing and hands of users, and the computer simulates real environments physical simulation, so the user feels immersed in this virtual world. That exposure to VR has the ability to create a sense of realism in a safe environment under the supervision of a therapist capable of guiding the patient through a series of gradual exposure exercises, where the frightening stimulus is simulated in a safe virtual environment, and exposure to $\mathrm{VR}$ is still a new technique not adopted in clinical care routine due to the cost of equipment used in this type of treatment (Arnout 2020c; North et al., 1997; Riva et al., 2016).

The VR is a logical extension of the technological advancement of the computer, so that the user can interact with it, whether by examining what this environment contains through the senses of hearing and sight, or by participating and influencing it, by doing adjustments and development processes, which is a simulation of a realistic or imaginary environment that is conceived and built from using the potentials provided by modern technology, using sound, 
image and 3D graphics to produce life situations that attract people to interact with them (Gorini \& Riva 2008; LVZ et al., 2016).

\subsection{Stages of VRT}

According to Anderson et al. (2001), Gorini \& Riva (2008) and Rizzo et al. (1997) there are many stages of VRT, as following:

1. Reality: It is an environment that includes only real objects, and it includes the direct view of one of the scenes of the real world or the presentation of a traditional video of the same real scene.

2. Augmented Reality: It is a realistic environment that provides virtual objects or scenes produced by the computer, and these scenes are installed visually, or via virtual video scenes inside the real environment.

3. Augmented Virtually: It includes virtual environments, some of which are real scenes, whether they are real objects or video clips of a real environment.

4. Virtual Reality: It is an environment that includes only virtual objects, in which the user is completely immersed, and is able to interact with a completely artificial world.

\subsection{Benefits of VRT}

From LVZ et al. (2016), Rizzo et al. (1997) and Riva et al. (2016) point of view, VRT is very benefit because:

1. A better method of treatment. Research has shown that VRT relieves wound pain, burns, and dental treatment, but rather reduces labor pain and some minor surgical work.

2. Reduced need for medication: For many patients, the use of VR reduced their need for analgesics, especially those that cause habitual use. Rather, according to the testimony of one of the nurses who first doubts the matter, in some patients she reaches the complete disposal of painkillers.

3. Reducing the financial cost: This is in terms of reducing dependence on medicines in addition to reducing hospital stay periods, which save hundreds or even thousands of dollars sometimes.

4. Learning new health skills: Whoever knows the patient about the nature of his pain and how to treat it by using some medical programs in virtual reality, to teach the patient skills such as meditation and breathing regulation, among others. These skills help to pass the slow learning threshold, especially with pain. VR is faster in education in addition to providing a patient selfmonitoring system in order to monitor its success in treatment and this needs a group of specialized medical devices to compensate for that.

5. Improving movement and assisting with physical therapy in this: some patients need physical therapy in order to improve their condition, and this poses a challenge for them. Physical therapy is not easy, especially in its early stages. VRT has proven that these patients have improved their performance 
significantly by using this treatment and helped a lot in other cases that included movements benefiting the health of the heart, circulation and lungs. Movement in general and physical activity triggers a self-treatment course for the body.

The idea of VRT relies on taking advantage of the patients 'merging in a virtual three-dimensional environment, which simulates their previous experience in a safe and organized place, helping them to better meet their concerns of places and people. Exposure therapy using VR technology aims to transport the patient to a virtual world through headphones and a 3D studio, where he interacts with a video game-like environment equipped with visual, acoustic and sensory signals

\section{(Anderson et al., 2001; Gorini \& Riva 2008).}

Virtual technology builds an environment that fits the patient based on his memories and includes special sounds and visual cues based on the patient's description of events in order to add a realistic effect. For example, for patients with increased fear of flying, the experience may include the sound of the plane's engine. Sexual assault victims may see a scene depicting a man approaching a bus stop without pedestrians. According to researchers, the more patients interact with the virtual environment, the better their ability to remember until they become familiar with the scene, and healing stages begin when this familiarity ultimately succeeds in discouraging neurons that translate the feeling of fear into the amygdala, a part of the brain responsible for treating emotions and feeling fear (North et al., 1997; Riva et al., 2016; Rizzo et al., 2001).

The use of VR technology in therapy is gaining increasing popularity as one of the types of treatment with exposure that enters the patient without exposing him to danger to an experiment similar to what causes his anxiety or fear with the aim of treatment. This treatment method has proven effective for recovering from PTSD and is usually caused by psychological or physical trauma, or a person's life is seriously threatened, that is why we desperately need VR therapy techniques to recover from COVID-19 disturbances.

\section{Conclusions}

Individuals of different age groups, social groups, educational level and income, whether they are ordinary or those with special needs, will suffer from one or more psychological problems related to COVID-19, as well as other stresses they suffer from such as losing a job or a dear person or job, wars and poverty, and daily frustrations. All of these conditions that humans live in through the outbreak of the COVID-19 pandemic show the need of community members for psychological counseling and therapy face-to-face, or online using the techniques of positive psychology with hope, mindfulness, resilience, gratitude, ACT etc., to increase their well-being and reduce their psychological distress related to COVID-19. We also hope to activate VRT face-to-face with the therapist or online. In light of the continuation of 
the COVID-19 pandemic and the increase in cases of infection, and the world entering the second new wave of it, this requires strategic planning to meet the great challenges resulting from this, and the development of new policies to provide psychological services to members of society, policies for work ethics with them and the role of service providers in helping them overcome their psychological suffering. As well as, developing a training plan for psychological care providers on the theories and techniques of online counseling and treatment, and VRT, to develop their professional skills to provide effective psychological services.

\section{Conflict of Interest}

The author declares that there is no conflict of interest.

\section{Funding information}

Not applicable

\section{Acknowledgments:}

The author would like to express their gratitude to King Khalid University, Kingdom of Saudi Arabia for providing administrative and technical support.

\section{References}

Amram Y., 2007. The Seven Dimensions of Spiritual Intelligence: An Ecumenical Grounded Theory. Paper Presented at the $115^{\text {th }}$ Annual Conference of the American Psychological Association, San Francisco, CA, USA.

Amram Y., Dryer C., 2008. The integrated spiritual intelligence scale: development and preliminary validation. Paper presented at the $116^{\text {th }}$
Annual Conference of the American Psychological Association. Boston, MA.

Anderson P., Rothbaum B., Hodges L., 2001. Virtual reality: using the virtual world to improve quality of life in the real world. Bull Menninger Clin, 65: 78-91.

Arnout B., 2008. Spiritual Intelligence and its Relationship to Quality of Life. Journal of the Modern Education Association, 2: 313-389.

Arnout B., 2016. Spiritual intelligence and psychological counseling between theory and practice. Cairo: The Anglo-Egyptian Library.

Arnout B., 2018. The effectiveness of a program based on acceptance and commitment therapy and online to reducing the symptoms of bullying in a sample of faculty members. Alustath for educational and social studies Journal, 227: 27- 62.

Arnout B., 2019a. Applications of positive psychology in counseling and psychotherapy. LAMBERT for Academic Publishing, Germany.

Arnout B., 2019b. Spiritual Intelligence and Human Homeostasis. LAMBERT for Academic Publishing, Germany.

Arnout B., 2019c. Effectiveness of counseling eclectic program in developing spiritual intelligence of university students. Journal of educational and psychological Sciences, 27(3): 1628.

Arnout B., 2019d. The effectiveness of a counseling program based on acceptance and commitment to the development of strong personality traits and psychological contentment 
among secondary school teachers: a comparative study between the traditional and online applications of the program. Educational Journal of the Faculty of Education, Sohag University, 63: 136.

Arnout B., Almadi K., AlQidimi f., 2019. The effectiveness of a gratitude program in the development of positive thinking among King Khalid University students. Al Fath Journal. College of Basic Education, Diyala University, Iraq, 78: 66-101.

Arnout B., 2020a. Counseling and Psychotherapy Programs. Scholars Press, Germany.

Arnout B., 2020b. Handbook of 21st Century Intelligence SQ. Scholars Press, Germany.

Arnout B., 2020c. COVID-19 Pandemic Crisis: And the New Face of The World. Scholars Press, Germany.

Arnout B., 2020d. Predicting psychological service providers' empowerment in the light of the COVID-19 pandemic outbreak: A structural equation modelling analysis. Counseling and Psychotherapy Research, 20(3): 406-418.

Arnout B., Al-Dabbagh Z., Al Eid N., Al Eid M., Al-Musaibeh S., Al-Miqtiq M., Al-Zeyad G., 2020.

The Effects of Corona Virus (COVID-19) Outbreak on the individuals' Mental Health and on the Decision Makers: A Comparative Epidemiological Study. International Journal of Medical Research \& Health Sciences, 9(3): 26-47.

Baer R., 2006. Mindfulness-based treatment approaches: clinician's guide to evidence base and applications. San Diego: Elsevier.
Bahreini Z., Sanagouye-Moharer G., 2019. Effectiveness of acceptance and commitment therapy on psychological well-being and resilience of abandon adolescents. Community Health, 6(1): 70-79.

Bai Y., Lin C., Lin C., Chen J., Chue C., Chou P., 2004. Survey of stress reactions among health care workers involved with the SARS outbreak. Psychiatric Services, 55(9): 1055-1057.

doi:10.1176/appi.ps.55.9.1055

Bartlett M., DeSteno D., 2006. Gratitude and prosocial behavior: Helping when it costs you. Psychological Science, 17: 319-325.

Bayati A., Abbasi P., Bashiri H., Dehghan F., Yazdanbakhsh K., 2017. The effectiveness of Acceptance and commitment therapy on psychological well-being in women with MS. Medical Science, 8(1): 82- 86.

Beddoe A., Murphy S., 2004. Does mindfulness decrease stress and foster empathy among nursing students? Journal of Nursing Education, 43(7): 305-312.

Brown K., Ryan R., 2003. The benefits of being present: mindfulness and its role in psychological well-being. Journal of Personality and Social Psychology, 84(4): 822-848.

Buzan T., 2001. The power of spiritual intelligence. New York, Harper Collins Publishers LTD.

Chen Y., Zhou H., Zhou Y., Zhou F., 2020. Prevalence of self-reported depression and anxiety among pediatric medical staff members during the 
COVID-19 outbreak in Guiyang, China. Psychiatry Research, 288: 113005.

https://doi.org/10.1016/j.psychres.2020.113005

Cicchetti D., 2010. Resilience under conditions of extreme stress: A multilevel perspective. World Psychiatry, 9(3): pp.145-154.

Costello M., 2013. How to increase your spiritual intelligence. Personal development.

Dirkzwager A., Bramsen I., Henk M., Ploeg V., 2003. Social support, coping, life events, and posttraumatic stress symptoms among former peacekeepers: a prospective study. Personality and Individual Differences, 34: 1545-155.

doi: 10.1016/S0191-8869(02)00198-8

Dubey S., Biswas B., Ghosh R., Chatterjee S., Dubey M. J., Chatterjee S., Lahiri D., Lavie C., 2020. Psychosocial impact of COVID-19. Diabetes \& Metabolic Syndrome: Clinical Research \& Reviews, 14: 779-788.

https://doi.org/10.1016/j.dsx.2020.05.035

Duckworth A., Steen T., Seligman M., 2005. Positive psychology in clinical practice. Annual Review of Clinical Psychology, 1: 629-651.

Emmons R., McCullough M., 2004. The psychology of gratitude. New York, NY: Oxford University Press.

Emmons R., 2007. Thanks! How the new science of gratitude can make you happier. New York: Houghton Mifflin Company.

Emmons R., Shelton C. 2002. Gratitude and the science of positive psychology. In C. R. Snyder \& S. J. Lopez (Eds.), Handbook of positive psychology (pp. 459-471). Oxford, United Kingdom: Oxford University Press.

Fernandez R., 2016. 5 Ways to Boost Your Resilience at Work. Harvard Business Review. Retrieved from https://hbr. org/2016/06/627-building-resilience-ic5-ways-to-buildyour-personal-resilience-at-work.

Froh J., Sefick W. Emmons R., 2008. Counting blessings in early adolescents: An experimental study of gratitude and subjective wellbeing. Journal of school psychology, 46(2): 213-233.

Gilbert C., 2016. Resiliency Training - Energy Management Strategies. Retrieved from: https://www.army.mil/article/177629/resiliency_tr aining_energy_management_strategies.

Gorini A., Riva G., 2008. Virtual reality therapy in anxiety disorders: the past and the future. Expert Rev Neurother, 8: 215-233.

Graham R, 2013. Bouncing Back: Rewiring Your Brain for Maximum Resilience and Well-Being. Novato, CA: New World Library.

Griffith J., West C., 2013. Master resilience training and its relationship to individual wellbeing and stress buffering among army national guard soldiers. Journal of Behavioral Health Services \& Research, 40(2): 140-155.

Hartwick J., Kang S., 2013. Spiritual practices as a means of coping with and ameliorating stress to reduce teacher attrition. Journal of Research on Christian Education, 22 (2): 165-188.

Jain S., Shapiro S., Swanick S., Roesch S., Mills P., Bell I., Schwartz G., 2007. A randomized 
controlled trial of mindfulness meditation versus relaxation training: effects on distress, positive states of mind, rumination, and distraction. Annals of Behavioral Medicine, 33(1): 11-21.

doi:10.1207/s15324796abm3301 2.

Kabat-Zinn J., 1990. Full catastrophe living: using the wisdom of your body and mind to face stress, pain and illness. New York: Delacorte.

Kabat-Zinn J., Massion A., Kristeller J., Peterson L., Fletcher K., Pbert L., Santorelli S., 1992. Effectiveness of a meditation-based stress reduction program in the treatment of anxiety disorders. The American Journal of Psychiatry, 149(7): 936-943.

Kim-Cohen J. 2007. Resilience and developmental psychopathology. Child and Adolescent Psychiatric Clinics of North America, 16: 271283.

Kimmons S. 2016. Army overhauls resilience program to focus on all Soldiers.

http://ncojournal.dodlive.mil/2016/12/30/armyoverhauls-resilience-program-to-focus-on-all-

soldiers/.

Kluge H., 2020. Statement e physical and mental health key to resilience during COVID-19 pandemic.

http://www.euro.who.int/en/health-topics/healthemergencies/COVID-19-COVID-

19/statements/statement-physicaland-mentalhealth-key-to-resilience-during-COVID-19pandemic.

Lambert N., Graham S., Fincham F., 2009. A prototype analysis of gratitude: Varieties of gratitude experiences. Personality and Social Psychology Bulletin, 35: 1193-1207.

Lancee W., Maunder R., Goldbloom D., 2008. Prevalence of psychiatric disorders among Toronto hospital workers one to two years after the SARS outbreak. Psychiatric services, 59(1): 91-95.

https://doi.org/10.1176/ps.2008.59.1.91

Levin M., Haeger J., Pierce B., Twohig M., 2016. Web-based Acceptance and Commitment Therapy for Mental Health Problems in College Students: A Randomized Controlled Trial. Psychology Faculty Publications. Paper 1091.

https://digitalcommons.usu.edu/psych facpub/1091

Liu S., Yang L., Zhang C., Xiang Y., Liu Z., Hu S., Zhang B., 2020. Online mental health services in China during the COVID-19 outbreak. Lancet Psychiatry, 7(4): e17-e18.

https://doi.org/10.1016/S2215-0366(20)30077-8.

Lopez S., Snyder C., 2003. Positive psychological assessment: A handbook of models and measures. Washington, DC: American Psychological Association.

LVZ, Chirivella J., Gagliardo P., 2016. Big data Oriented Multimedia Mobile Health Applications. J Med Syst, 40(5),120. doi: 10.1007/s10916-0160475-8. Epub 2016 Mar 28.

McCullough M., Kilpatrick S., Emmons R., Larson D., 2001. Is gratitude a moral affect? Psychological Bulletin, 127: 249-266.

McCullough M., Tsang J., 2004. Parent of the virtues? The prosocial contours of gratitude. In R. Emmons \& McCllougue (Eds). The psychology of 
gratitude (pp.123-141). New York: Oxford University Press.

North M., North S., Coble J., 1997. VRT: an effective treatment for psychological disorders. Stud Health Technol Inform, 44: 59-70.

Orsillo S., Batten S., 2005. Acceptance and Commitment Therapy in the Treatment of Posttraumatic Stress Disorder. Behavior Modification, 29(1): 95-129.

Riva G., Baños R. M., Botella C., Mantovani F., Gaggioli A., 2016. Transforming Experience: The Potential of Augmented Reality and VR for Enhancing Personal and Clinical Change. Front Psychiatry, 30: 7-164.

doi: 10.3389/fpsyt.2016.00164. eCollection 2016.

Rizzo A., Buckwalter J., Neumann U., 1997. Virtual reality and cognitive rehabilitation: A brief review of the future. J Head Trauma Rehabil, 12: $1-15$.

Saeed, H.; Ahmad, A.; Farah, N.\& Mehdi, M. (2016). The effectiveness of acceptance and commitment therapy (ACT) on test anxiety and psychological well-being in high-school students. International Journal of Humanities and Cultural Studies, Special Issue, 1-35.

Seligman M., 2002. Authentic happiness: Using the new positive psychology to realize your potential for lasting fulfillment. New York: Free Press.

Seligman M., Rashid T., Parks A. 2006. Positive psychotherapy. American Psychologist, 61: 774788.

Tabrizi F., Nameghi A., 2017. Effectiveness of acceptance and commitment therapy on psychological well-being and anger reduction among mothers with deaf children in Tehran. Aud Vest Res, 26(3): 151-156.

Teasdale J., Segal Z., Williams J., Ridgeway V., Soulsby J., Lau M., 2000. Prevention of relapse/recurrence in major depression by mindfulness-based cognitive therapy. Journal of Consulting and Clinical Psychology, 68(4): 615623.

Tsang J., 2006. Gratitude and prosocial behavior: An experimental test of gratitude. Cognition and Emotion, 20: 138-148.

Vostanis P., Bell C., 2020. Counselling and psychotherapy post-COVID-19. Couns Psychother Res, 20: 389-393.

https://doi.org/10.1002/capr.12325

Yeager D., Dweck C., 2012. Mindsets that promote resilience: When students believe that personal characteristics can be developed. Educational psychologist, 47(4): 302-314. 